\title{
Disinfectants in Laboratory Animal Science: What Are They and Who Says They Work?
}

\author{
Amy Ingraham, BA, RLATG and Tammy Marotta Fleischer, ABS, QC
}

Two thousand years ago-well before government regulations for disinfectants, sterilants, and sanitizers existed-the Bible, various Eastern religious writings, and sacred tomes extolled the virtues of personal hygiene, dietary considerations, and "what to do when all else fails" blueprints for remaining healthy. Even Greek literature contains precise standard operating procedures (SOPs) to rid inanimate objects of microbial pathogens: In The Odyssey, Homer refers to 'fumigating' Odysseus' house by burning sulfur; Aristotle advised, "Bury your dung."

The entire scientific pursuit of microbiology was of course unknown at the time, and not until the 1400s did the invention of the microscope allow people to see the world of microbes. It was Robert Koch's germ theory of disease during the 1880s that established the role of microbes as the cause of disease ${ }^{1}$.

Although they were often effective, early attempts at disinfection were not always pragmatic. Sir Joseph Lister flooded the skin of patients undergoing surgery with carbolic acid, causing skin burns but preventing the development of nosocomial illnesses. Even though the use of fire was recognized as a means to 'disinfect' inanimate objects, it was not always practical to burn down a building to kill the microbes it contained.

The ability to rid the laboratory or animal facility of potentially harmful microorganisms is no less important today. In this article we discuss the various types of liquid disinfectants that can be used on surfaces such as floors and tabletops, and clarify how these products are registered in the United States.

\section{Definitions}

A disinfectant is an agent that will destroy or eliminate from inanimate objects all pathogens except bacterial endospores. A sterilant will destroy or eliminate pathogens, including bacterial endospores, from inanimate objects. Disinfectants include products that are virucidal, bactericidal, and fungicidal. Sterilants are biocidal, because by definition they will kill all living organisms, both pathogenic and nonpathogenic. The term 'germicide' is synonymous with 'disinfectant'.

Microorganisms have different levels of resistance to chemical disinfection. Resistance varies with the type of organism. For instance, bacterial spores are very difficult to kill, whereas the HIV virus is rather easy to eradicate on hard surfaces. Infectious prions (e.g., the causative agent in bovine spongiform encephalopathy (BSE), or mad cow disease) are not included in this group because the prion is technically not a cellular microorganism but rather a protein. At this time there are no documented chemical or physical agents that will inactivate these infectious proteins. Similarly, there is no registered germicide that can with certainty kill pinworm eggs, although a simple ammonia solution will kill the ova of other parasites (e.g., Cryptosporidium parvum ${ }^{2}$ ).

Table 1 lists types of microorganisms in descending order of resistance to chemical germicides. A germicide at a given level of

TABLE 1. Types of microbes, listed in descending order of resistance to chemical germicides $^{\mathrm{a}, \mathrm{b}}$.

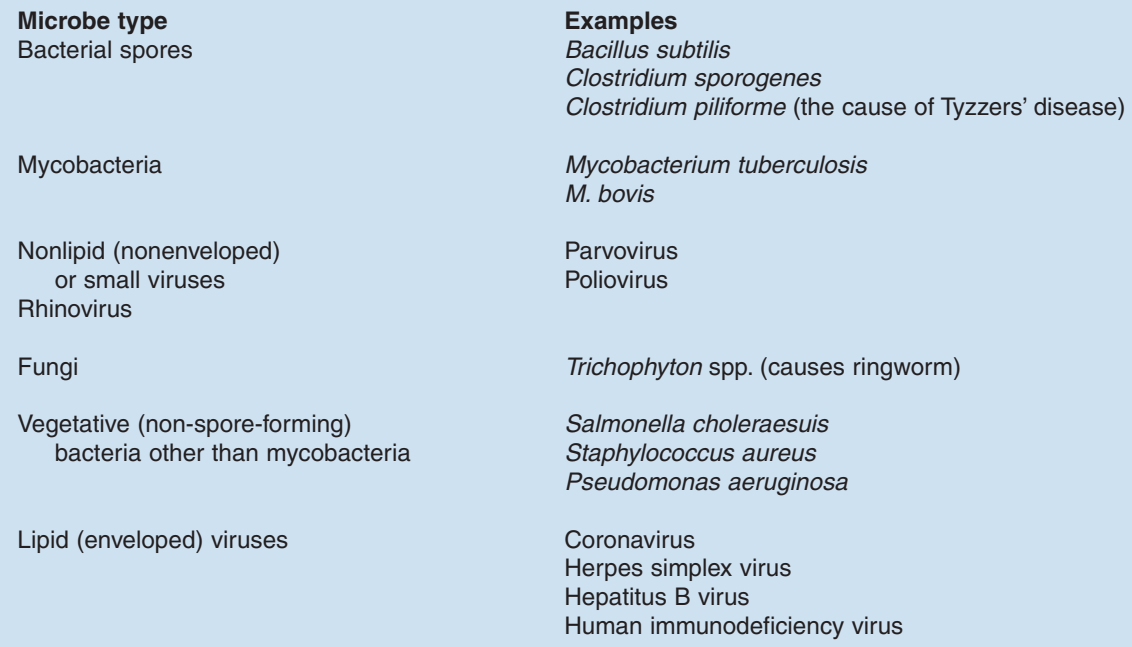

Lipid (enveloped) viruses

Coronavirus

Herpes simplex virus

Hepatitus $B$ virus

Human immunodeficiency virus

See refs. 10, 11

bNote: Infectious prions and parasitic oocytes are not included. 
effectiveness should inactivate or kill all organisms located at that level and on the lower levels of resistance. Apart from prions and parasite ova, bacterial spores are the life form that is most difficult to kill, so the Food and Drug Administration (FDA) uses biological indicators that contain bacterial spores to prove sterilizing efficacy. Notice that this list does not contain protozoan cysts. Pinworm eggs are very persistent in the laboratory animal facility, and are usually able to tolerate chemical germicides. To rid a facility of the cysts, it is advisable to consider 'cooking' them with steam heat. Like an egg, they will harden and become inactive when heated.

\section{Delineations of Authority}

In the US, the Environmental Protection Agency (EPA) registers commercially manufactured disinfectants under regulations set forth in the Federal Insecticide, Fungicide, and Rodenticide Act (FIFRA) as amended $^{3}$. Chemical disinfectants are referred to as "pesticides" in these federal acts.

The first FIFRA, enacted in 1947, was essentially a 'truth-in-advertising' law, because its goal was to protect the public from false or exaggerated claims made for certain products that were sold across state lines. In 1972, the government extensively modified the FIFRA so that it now requires a manufacturer to submit not only an application but also a label clearly stating all claims, test data from an EPA-certified laboratory supporting these claims, toxicology data, a "confidential statement of formula", and precise "use directions". The "confidential statement of formula" will include specific ranges for every ingredient included in the product as well as a description of that ingredient's function in the formulation. The confidential statement must also list Chemical Abstracts Service (CAS) numbers and approved raw material vendors. A pesticide label must include a list of active ingredients with their amounts, storage, and disposal information. The label must also have precautionary statements, first-aid instructions, the manufacturer's complete address, and an EPA registration number. If a product does not have an EPA registration number, then it should not be used for disinfection in an animal-care area.

In 1982, the government once again amended the FIFRA to clarify terminology. Before this clarification, a "sporicide" and a sterilant were two separate classifications. A "sporicide" could have one failure out of 60 replicates in a sporicidal assay, and the "sterilant" could have no failures in the same assay. These new regulations considered sporicides and sterilants as the same.

The FDA classifies differently products that disinfect surfaces and those used to sterilize medical devices. The FDA registers products that are liquid sterilants, and the EPA registers products that are disinfectants. EPA-registered disinfectants may not be used as terminal sterilants on any surface or instrument that is introduced directly into the human body or that comes in contact with normally sterile areas of the body or the bloodstream.

A sterilant (sporicide) is capable of destroying all forms of microbial life. Sterilants are the most potent and are effective against all forms of vegetative bacteria, bacterial spores, fungi, fungal spores, and viruses. An FDA-registered liquid chemical sterilant will completely eradicate all of the microorganisms listed in Table 1.

A high-level disinfectant should eradicate all microbes except for bacterial spores. An intermediate-level disinfectant should eradicate enveloped viruses and all the lessresistant microbes. A low-level disinfectant must kill only three species of bacteria: Salmonella choleraesuis, Staphylococcus aureus, and Pseudomonas aeruginosa. Incredibly, there is also a category of disinfectants below that of a low-level disinfectant. These products, called "hospital disinfectants", must only kill S. choleraesuis and $S$. aureus.

\section{Types of Disinfectants Used in Laboratory Animal Science lodines and Phenols}

Iodine compounds are disinfectants that can kill many kinds of microorganisms, including both enveloped and nonenveloped viruses. Iodines appear to work by penetrating the cell wall of the organisms, causing a disruption of the cell metabolism and function. Secondarily, free iodine may bond in solution with the cell proteins to form salts ${ }^{4}$. Iodine compounds are poor cleaners, requiring the use of another chemical to clean the surface. In addition, iodines are relatively unstable in terms of contact time and light exposure, and can permanently stain surfaces if not used properly. Extensively used during the 1960s, iodines imparted a permanent brown discoloration to floors and walls. Perhaps most importantly of all, iodophors are only active within tight brackets of concentration. Increasing the concentration may actually reduce the available iodine in the aqueous solution $^{5}$. Additionally, microorganisms, specifically Pseudomonas cepacia, have been cultured from full-strength povidone-iodine products ${ }^{6}$.

Phenolic compounds are broad-spectrum disinfectants that can kill both enveloped and nonenveloped viruses as well as mycobacteria. Phenolics appear to kill microorganisms by penetrating the cell wall and acting as cell poisons, or by denaturing the cell's proteins ${ }^{4}$. These compounds are extremely corrosive and require exceptional precautions in handling. Phenolics are extremely hazardous to cats, cause skin depigmentation, and have posed human health problems ${ }^{4,7}$.

In the past, the phenol coefficient has been the standard against which all other disinfectants were judged. This standardization included comparing germicidal chemicals and provided an index to the concentration of other products. The errors inherent in converting phenol coefficient numbers to effective dilutions of products for practical disinfection are so great that the procedure must be considered unsatisfactory, particularly for nonphenolic compounds. Currently, the Association of Official Analytical Chemists (AOAC) use dilution test remains the standard for determining the efficacy of disinfectants; however, the government has provided funding to establish alternative assays, each with an exact number of microorganisms per challenge. These assays should soon be adopted. 


\section{Chlorine Compounds}

Sodium hypochlorite. Sodium hypochlorite (the active ingredient in bleach) is perhaps the best example of a chlorine compound used as a disinfectant. If used within some rather stringent parameters, bleach is a very effective and relatively inexpensive virucidal product. The mode of action of chlorine compounds is not fully understood. Chlorine compounds may actually cause cell death by a two-step process, reacting with the cell protoplasm after forcing entry through the cell wall, or perhaps by inhibiting the cell enzyme reactions and denaturing the cell proteins ${ }^{4,7}$.

People have used bleach as a disinfectant since the early 1800s (ref. 8). During World War I, H.D. Dakin advocated the use of a $0.50 \%$ solution of sodium hypochlorite for skin and open wound disinfection; many contemporary primate laboratories have a prepared bottle of Dakin's solution in the emergency monkey bite kit. The ElectroAlkaline Company (later the Clorox Company) began the American production of commercially available sodium hypochlorite solution in 1913. Hospitals and critical care facilities today accept sodium hypochlorite solution as an inexpensive disinfectant ${ }^{9}$.

Concerns about the efficacy of sodium hypochlorite have involved the percentage of active chlorine required to provide antimicrobial properties. Reports from the field have shown that prepared bleach solutions rapidly lose potency under ambient laboratory conditions. An organic soil load reduces sodium hypochlorite's effectiveness as a disinfectant, necessitating a precleaning step before disinfection. Bleach has an inherent corrosive effect on certain metals, concrete, and clothing, and can pose problems for animals and personnel.

Among these problems is bleach's reactivity with acids, releasing chlorine gas, which is highly toxic. It also reacts with organic soils (e.g., feces) to produce potentially carcinogenic compounds. One resulting compound, trihalomethane, can be released as a toxic gas. Therefore, supervisors must carefully consider the use of bleach and ensure when making up a bleach-water solution to maintain adequate chlorine concentrations (i.e., 100 p.p.m.).

Sodium hypochlorite is highly reactive and degrades rather quickly. Thus, as Fig.1 shows, bleach rapidly loses its effectiveness as sodium hypochlorite degrades. The Quality Assurance Laboratory of Pharmacal Research Laboratories conducted a test that simulated normal laboratory storage conditions. We stored a simple solution of $18.0 \%$ sodium hypochlorite in an opaque bottle that was capped and left on a countertop in the laboratory to simulate a bleach bottle stored on the shelf at room temperature. The overhead lights were turned on in the morning and off at night 5 days a week, allowing for $\sim 9 \mathrm{~h}$ of illumination per day. We locked the laboratory and left it vacant during the weekends. For a 70-day period we analyzed daily samples from the bottle and recorded the percentage of active sodium hypochlorite in the sample. Our results showed an initial decelerating curve of degradation of the percentage of active sodium hypochlorite. At 5 days, the solution measured $15.68 \%$ sodium hypochlorite; at 20 days it was $13.72 \%$. At 35 days, the percentage was $12.74 \%$ with the rate of degradation substantially decreased. The shelf life of commercially available sodium hypochlorite mixtures (bleach) will depend on the storage facility, temperature controls, light controls, etc. Facility managers should label and check the product regularly using available chlorine detection strips or test kits.
Chlorine dioxide. Chlorine dioxide is available as a high-level disinfectant that has wide applicability not only in the animalcare field but also in the manufacturing and paper industries. Health officials used chlorine dioxide to remove the anthrax contamination in the Hart Senate Building in 2001. Manufacturers use it in toothpaste, for instance, as well as in paper and pulp manufacturing. It is necessary to mix the product on site, and its shelf-life is inherently short and of mixed product efficacy.

Chlorine dioxide is a free radical and a powerful oxidant that kills microbes by reacting with bacterial and viral amino acids. Chlorine dioxide requires a very short contact time but does not have inherent cleaning ability, necessitating a precleaning step. All chlorine dioxide products currently available have inherent acidity and corrosive properties. Chlorine dioxide's entry into the animal-care area has allowed supervisors to use one product rather than two or three different disinfectants to carry out the same process in a short period. One should not confuse chlorine dioxide with chlorine gas; they are two completely different chemicals.

\section{Quaternary Ammonium Compounds}

Of the many disinfecting compounds currently available, the quaternary ammonium compounds are the most widely used in animal facilities. There are five possible modes of action for quaternary ammonium

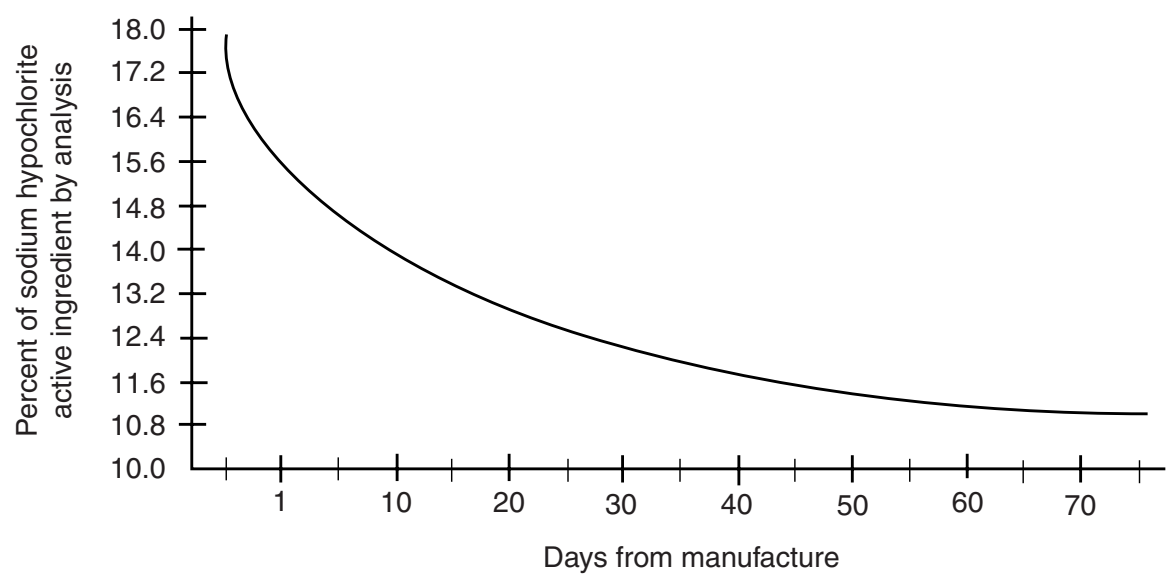

FIGURE 1. Degradation of sodium hypochlorite over time. (Data from Pharmacal Research Laboratories, Naugatuck, CT). 
products: denaturing cell proteins, influencing cell metabolic reactions, affecting cell permeability, stimulating cell glycolysis reaction, and affecting cell membrane enzyme activity ${ }^{7,10}$. They are relatively cost effective, easy to use, and, if handled properly, safer for animals and people than the other currently available disinfectants. These compounds are generally not tuberculocidal. The newest quaternary ammonium compounds generally meet most of the cleaning-disinfecting requirements.

The first generation of quaternary ammonium compounds became available in 1935. Dilution with hard water or with the wrong type of soap or detergent can inactivate these earlier generation quaternary ammonium compounds. Therefore, it is extremely important to obtain a quaternary disinfectant that has been properly compounded with compatible nonionic detergents, which will not affect its disinfecting properties. The newest generation quaternary ammonium compounds are generally blends of alkyl dimethyl benzyl ammonium chloride (ADBAC) quaternary ammonium compounds, rather than the old single-chain compounds. A good quaternary ammonium compound should remain active as a virucidal, fungicidal and bactericidal agent when subjected to the AOAC use dilution test, in 400 p.p.m. hard water plus 5\% organic serum. The EPA registration number on the label certifies only that the product is a disinfectant, not that it is a cleaning product. While quaternary ammoniums have inherent cleaning abilities, the addition of a cleaning agent increases the ability of the product both to clean and to disinfect.

The newer generation of quaternary ammonium compounds will kill some nonenveloped viruses as well as enveloped viruses.

\section{Glutaraldehyde}

A member of the aldehyde group that includes formaldehyde, glutaraldehyde has limited use in the animal-care facility. Glutaraldehydes work by alkylating amino acids to alter RNA, DNA and protein synthesis $^{4,7}$. The necessary contact time required for high-level disinfection is quite long, and there are several questions concerning the safety of these products for people and animals. Glutaraldehyde is tuberculocidal. The tendency of glutaraldehydebased sterilants to induce contact dermatitis has led health care facilities to limit its use in recent years because of liability issues ${ }^{4,9}$.

\section{Alcohols}

Alcohol products denature cell proteins to cause cell death. However, they can quickly become ineffective in protein-rich environments. Because of their volatile characteristics, the use of alcohol products as primary disinfectants has declined. Contact time for alcohol products can range up to several hours, which can be difficult considering their highly evaporative nature. Also, alcohols can damage rubber and plastic components ${ }^{4}$.

\section{Peroxygen Compounds}

The search for the 'perfect' disinfectant may lead to peroxygen products such as hydrogen peroxide, which is a sterilant at the appropriate concentrations. Peroxygen compounds act as rapid oxidizers to cause cell death or inactivation. Once known as oxidized water or peroxymonosulfates, peroxygen compounds have come to the laboratory animal care field as part of a search for products that are environmentally friendly and relatively low in toxicity for use around animals. Many of the peroxygen products leave no residuals and have excellent germicidal activities. Peroxygen products came to the forefront when foot-andmouth disease appeared in the United Kingdom in 2000. These products are very strong oxidizers, and their germicidal activity occurs quickly, that is, only a short contact time eradicates microbes. Peracetic acid is a peroxygen product. Hydrogen peroxide when used in the vapor phase is a sterilant.

\section{Product Testing and Registration}

A germicide's EPA registration number is a 'stamp of authenticity' for the product. Under FIFRA, the EPA issues registration numbers for chemical disinfectants after reviewing the product's claims of efficacy. These claims result from testing in strict compliance with the requirements set by the EPA, which thoroughly reviews the data submitted about the product. The EPA will issue a registration number specific to the particular product only if all the necessary data have been submitted to support the claims. Once the EPA issues a number, the manufacturer may not alter the product's chemical composition unless it provides the EPA with test data proving the product still retains the capabilities to support the original claims.

The AOAC use dilution test is an extensive evaluation of germicides that employs hard water with organic serum added, in an attempt to simulate 'real-world', worst-casescenario challenges. This test assesses claims that a given germicide will kill vegetative bacteria.

Testing a product for its ability to deactivate spores is more extensive. After inoculation of penicylinders (porcelain cylinders) and surgical loops with specific microorganisms, one vacuum-dries them, making the pathogen even more resistant to penetration and killing by the disinfectant. Then one exposes the cylinders or loops to the specific product in the proposed use dilution. After a specified period, which follows the manufacturer's claims for kill time, the testers are removed and placed in a culture medium. The literature that the manufacturer submits to the EPA will include the recommended exposure time for the product to achieve a complete kill. The sporicidal test involves either B. subtilis or C. sporogenes. Analysts examine the resulting growth for the specific microorganism. They repeat this process extensively, and the chemical being tested must prevent growth in 60 of 60 tests for a total of 12 sets of tests involving 360 penicylinders and 360 surgical loops, and three lots of each product

Critics have questioned the efficacy of these tests in recent years. Inconsistencies are common within a testing lab and between various laboratories ${ }^{11}$. Scientists have cultured the microorganisms in laboratories for generations, and the cultures 
may not react, as would a 'wild-type' culture freshly isolated from the field. The tests specify a minimum, but not a maximum number of microorganisms per assay, and this can of course drastically affect the test results. The result has been perhaps a false sense of security about the effectiveness of particular products. Since 1991, the EPA has been reevaluating the specific claims of many germicides. Some products that had been listed as "sterilants" before 1991 were reclassified as "high-level disinfectants" after these reevaluations (see www.epa.gov/pesticides).

\section{What to Look For}

When evaluating disinfectants for animal-care facilities, the first concern should be finding the EPA registration number. Claims for disinfectants that are unregistered may not be substantiated. For instance, household bleach is a common product found in many laboratory animal facilities. Only a few manufacturers of household bleach have EPA-registered numbers for their products. The other companies are manufacturing a product that will clean and brighten your clothes, but may not disinfect your facility. In fact, the percentage of active ingredients in these products may be too low for effective sanitizing.

Within the field of laboratory animal science, the same registration numbers can appear on different chemical vendors' products. The vendor from whom you are purchasing the product may not hold the master registration number. Companies can subregister the formulation from the company holding the master label. Therefore, a registration number or part of a registration number may be used on products with different names. The EPA must approve any subregistration, and the subregistrant designs its own label after having received EPA approval. These labels cannot add any claims that the master label does not have and must be submitted to the holder of the master registration for approval.

An EPA registration number can look like this: 1234-56. This number tells us that the company holding the master registration has an establishment number of 1234, and the 56 identifies the product. A registration number of 1234-56-789 indicates that the product is subregistered. The first set of numbers (1234) is the establishment number for the holder of the master registration, the 56 identifies the product, and the 789 is the subregistrant's establishment number.

A product's EPA registration number allows the user to obtain any necessary information on the product by consulting the list of registered pesticides in the United States. From there, one can determine who holds the master registration, whether it is subregistered, contact addresses and phone numbers, and all active ingredients and their percentages.

\section{Acknowledgments}

The authors thank Roger Orcutt for his suggestions in preparing this manuscript.

Received 11/20/02; accepted 12/2/02.

\section{References}

1. Koch, R. The etiology of tuberculosis [Koch's postulates.]. Mittheilungen aus dem Kaiserlichen Gesundheitsamte 2, 1-88 (1884).

2. Jenkins, M.B., Bowman, D.D. \& Ghiorse, W.C. Inactivation of Cryptosporidium parvum oocysts by ammonia. Appl. Environ. Microbiol. 64, 784-788 (1998).

3. 7 USC Chapter 125. Federal Insecticide, Fungicide, and Rodenticide Act (FIFRA). http://www.epa.gov/pesticides/fifra.htm.

4. Ingraham, A.S. The chemistry of disinfectants and sterilants. Contemp. Top. Lab. Anim. Sci. 31, 18-23 (1992).

5. Gottardi, W. in Disinfection, Sterilization and Preservation $4^{\text {th }}$ edn (ed. Block, S.) 152-166 (Lea \& Febiger, Philadelphia, PA, 1991).

6. Favero, M.S. \& Bond, W.W. in Disinfection, Sterilization and Preservation 4th edn (ed. Block, S.) 633-634 (Lea \& Febiger, Philadelphia, PA, 1991).

7. Rutala, W.A. APIC guideline for selection and use of disinfectants. 1994, 1995, and 1996 APIC Guidelines Committee. Association for Professionals in Infection Control, Inc [see comments]. Am. J. Infect. Control 24 313-342 (1996).

8. Dychdala, G.R. in Disinfection, Sterilization and Preservation 3rd edn (ed. Block, S.S.) 157-172 (Lea \& Febiger, Philadelphia, PA, 1983).

9. Rutala, W.A. Draft guideline for selection and use of disinfectants. Am. J. Infect. Control 17, 24A-35A (1989).

10. Mlynarcik, D., Denyer, S.P. \& Hugo, W.B. A study of the action of a bisquaternary ammonium salt, an amine oxide and an alkoxy phenylcarbamic acid ester on some metabolic functions in Staphylococcus aureus. MICROBIOS 30, 27-35 (1981).

11. Orcutt, R.P. Evaluation of disinfectants and sterilants. Contemp. Top. Lab. Anim. Sci. 30 15-18 (1991).

12. Spaulding, E.H. Chemical disinfection and antisepsis in the hospital. J. Hosp. Res. 9 , 5-31 (1972).

The authors are affiliated with Pharmacal Research Laboratories, 33 Great Hill Rd., Naugatuck, CT 06770. Please send reprint requests to Fleischer at the above address, or email: tmarotta@pharmacal.com. 